\title{
An Assessment of Total Polyphenolic Content and Antioxidant Potential of Mauby Bark Extracts (Colubrina arborescens) Brewed for Different Lengths of Time
}

\author{
Jeremy Embola ${ }^{1}$, Cheryl Rock ${ }^{1}$, Long Wang ${ }^{1}$, Wendy Reiboldt ${ }^{1}$, Saba Ahmed ${ }^{1} \&$ Simindokht Aliabadi $^{1}$ \\ ${ }^{1}$ Department of Family and Consumer Sciences, California State University, Long Beach, CA 90840, USA \\ Correspondence: Cheryl Rock, Department of Family and Consumer Sciences, California State University, Long \\ Beach, CA 90840, USA. E-mail: cheryl.rock@ csulb.edu
}

Received: October 28, 2018

Accepted: November 15, $2018 \quad$ Online Published: April 2, 2019

doi:10.5539/jfr.v8n3p26

\author{
URL: https://doi.org/10.5539/jfr.v8n3p26
}

\begin{abstract}
Mauby bark (Colubrina arborescens) is commonly used to make a beverage,"Mauby", in the Caribbean and is believed to possess antiglycemic, antilipidemic, and anticarcinogenic properties. However, limited studies have been conducted to substantiate the compounds present that may confer these benefits. Therefore, the objectives of this research were to quantify the total polyphenolic content and evaluate the antioxidant capacity of Mauby bark extracts brewed in water at 30, 45, and 60 minutes. In the extracts, the Total Flavonoid Content (TFC) ranged from $1.93-3.17 \mathrm{mg} \mathrm{CE} / \mathrm{mL}$ and the Total Phenolic Content (TPC) ranged from $2.10 \mathrm{mg} \pm 0.11 \mathrm{GAE} / \mathrm{mL}$ (45 minutes) - $2.36 \mathrm{mg} \pm 0.067 \mathrm{GAE} / \mathrm{mL}$ (30 minutes). Moreover, their antioxidant activity was assessed using the 2,2 Diphenyl 1-Picrylhydrazyl (DPPH) and Ferric Reducing Antioxidant Power (FRAP) assays. The DPPH scavenging activity observed from Mauby extracts ranged from 75\% \pm 4.02 (30 minutes) to $83 \% \pm 0.66$ (60 minutes) and the FRAP values ranged from $6.29 \pm 0.84$ (30 minutes) to $6.90 \pm 1.54 \mathrm{mM} \mathrm{FeSO}_{4}$ equivalents/ 0.2 $\mathrm{mL}$ Mauby extract (45 minutes). Although, polyphenolic content at 30 minutes was greater than 60 minutes of brewing for TFC $(p<0.001)$ and TPC $(p=0.002)$, the scavenging activity was greater at 60 minutes than 30 minutes $(p=0.014)$ while antioxidant power was not affected by brewing time $(p=0.736)$. In summary, brewing the bark at 60 minutes was observed to provide the highest antioxidant activity.
\end{abstract}

Keywords: beverage, Caribbean, Ethnomedicine, tree bark

\section{Introduction}

Mauby bark (Colubrina arborescens) (Figure 1) which belongs to the Rhamnaceae family (i.e. Buckthorn) is indigenous to the tropical regions of Central America and Florida (Johnston, 1971) where it is widely consumed as a beverage believed to possess medicinal properties (Alleyne, Roache, Thomas, \& Shirley, 2005). Previous research (Alleyne et al., 2005; Smith, 2012) suggests that Mauby bark extracts may reduce the prevalence of hypertension and diabetes. Additionally, Mauby bark extracts have been used through ethnomedicinal practices to alleviate inflammation due to rheumatism and possesses diuretic properties (World Agroforestry Centre [WAC], 2017). Conventionally, Mauby bark extract is produced by brewing the bark and extracting the liquid which is believed to be rich in polyphenolic compounds attributing to its hypothesized medicinal benefits (Barbados Pocket Guide, 2011). Notably, polyphenols are extensively studied due to their ability to reduce or prevent chronic illnesses in humans which may be applicable to studies involving Mauby bark extracts. 


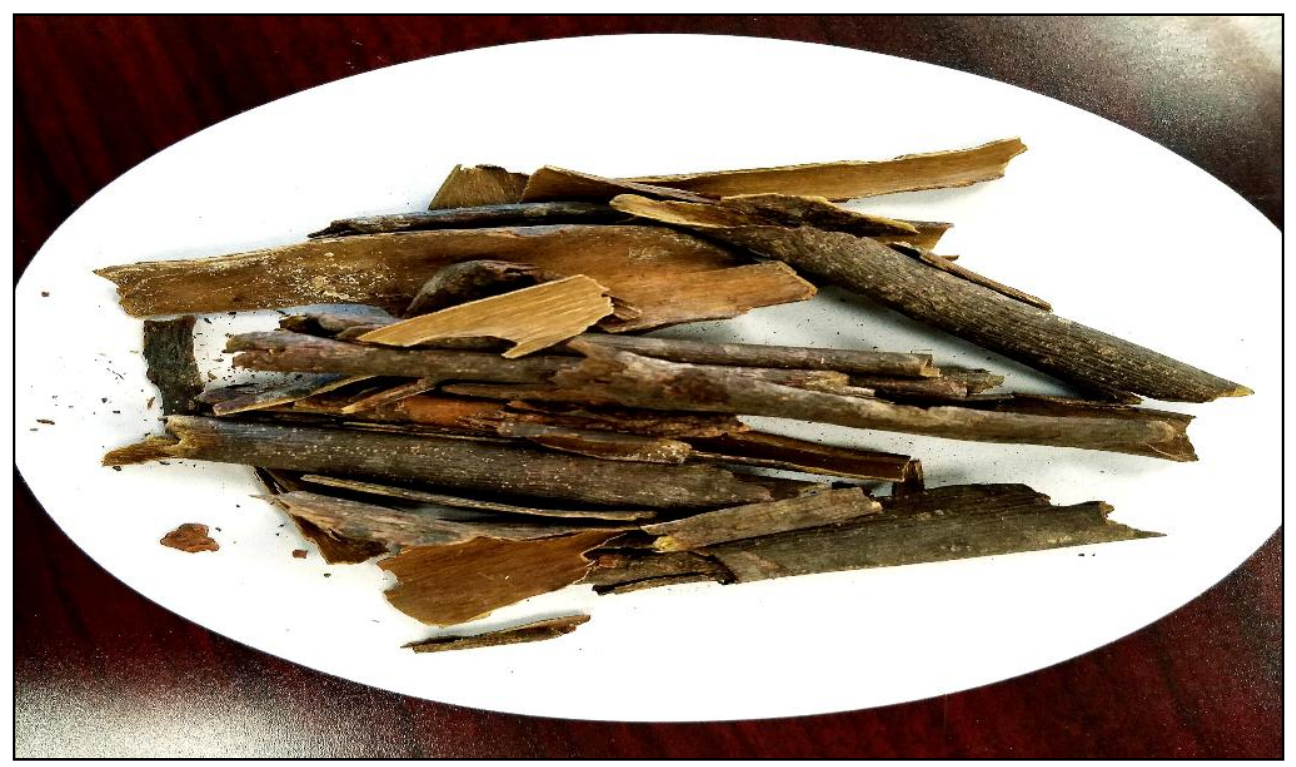

Figure 1. Mauby bark

Photo Courtesy: J. Embola and C.Rock

Polyphenols are molecules synthesized in plants to provide protection against ultraviolet radiation (UV) and pathogens (Manach, Scalbert, Morand, Remesy, \& Jimenez, 2004; D'archivio et al., 2007). Additionally, polyphenols act as dietary antioxidants by scavenging free oxygen radicals to reduce the risk of acquiring chronic illnesses related to oxidative stress (OS) (Manach et al., 2004; D'archivio et al., 2007). To illustrate the role of dietary polyphenolic intake among individuals with diabetes, flavonoids found in plants can decrease the rate of oxidative damage through inhibiting the oxidation of $\beta$-cells and stabilizing reactive oxygen species (ROS) (Patel, Kumar, Laloo, \& Hemalatha, 2012). Mauby bark and its associated beverages are widely consumed and commercialized throughout the Caribbean, but are not extensively studied as exemplified by limited studies. More research is needed to substantiate the compounds present that may confer these benefits regarding its polyphenolic and antioxidant properties. Therefore, the dissemination of Mauby bark benefits is hindered until analyzed and verified. Furthermore, the use of ethnomedicinal tree barks established globally in commercial food applications is novel in the Unites States. Thus, the overall objective of this experimental study was to quantify the total polyphenolic content and assess the antioxidant potential of Mauby bark extract using different brewing times to provide information that may explain attributes relative to its proposed health benefits.

\section{Materials and Methods}

\subsection{Mauby Extract Preparation}

First, Mauby bark (obtained by a third party vendor) was ground into a fine powder using a blender. Next, twenty grams $(20 \mathrm{~g})$ of Mauby bark powder was added to $250 \mathrm{~mL}$ of boiling water at $100^{\circ} \mathrm{C}$ with $5 \mathrm{~g}$ of boiling chips for 30 minutes. Furthermore, the same quantity of powder was used for 2 additional batches and brewed for 45 minutes and 60 minutes respectively. The treatments selected were similar to times Mauby bark is brewed by native Caribbean consumers. Once the Mauby bark samples were brewed for their respective times, the extracts were centrifuged at 4,000 revolutions per minute (RPM) for 10 minutes at $4^{\circ} \mathrm{C}$ using a Thermo Scientific Sorvall ST 8 R centrifuge and diluted (1:10) for subsequent analyses.

\subsection{Total Flavonoid Content (TFC) of Mauby Extracts}

The TFC of Mauby bark extracts were measured according to the methodology described by Marinova, Ribarova, and Atanassova (2005). First, a catechin standard curve was created from a stock solution of a concentration of $100 \mathrm{mg} / 100 \mathrm{~mL}$ to make five catechin standard solutions of varying concentrations $(0.2,0.4,0.6,0.8$ and 1.0 $\mathrm{mg} / \mathrm{mL}$ ). Next, $1 \mathrm{~mL}$ of each standard as well as diluted Mauby extracts were pipetted into $10 \mathrm{~mL}$ volumetric flasks, containing $4 \mathrm{~mL}$ of deionized distilled water $\left(\mathrm{DDH}_{2} \mathrm{O}\right)$. Furthermore, $0.3 \mathrm{~mL}$ of $5 \%$ Sodium Nitrate $\left(\mathrm{NaNO}_{2}\right)$ was added to each flask and held to incubate at room temperature $\left(\sim 25^{\circ} \mathrm{C}\right)$ for 5 minutes. Then, 0.3 $\mathrm{mL}$ of $10 \%$ Aluminum Chloride $\left(\mathrm{AlCl}_{3}\right)$ was added to each flask followed by $2 \mathrm{~mL}$ of $1 \mathrm{M}$ Sodium Hydroxide $(\mathrm{NaOH})$. Next, $6.4 \mathrm{~mL}$ of $\mathrm{DDH}_{2} \mathrm{O}$ was added to each flask to acquire a final volume of $10 \mathrm{~mL}$ and mixed 
thoroughly. The absorbance of each sample extract, which was a blue hue after addition of all reagents, was measured at a wavelength of $510 \mathrm{~nm}$ using an Ultraviolet (UV) spectrophotometer (Thermo Scientific AquaMate 8000 UV-Vis Spectrophotometer). Last, TFC results were expressed as $\mathrm{mg}$ catechin equivalents (CE)/ $\mathrm{mL}$ Mauby bark extract. All samples were analyzed in triplicate and averaged for statistical analysis.

\subsection{Total Phenolic Content (TPC) of Mauby Extracts}

The TPC of Mauby bark extracts were measured according to the methodology described by Marinova et al. (2005). First, a gallic acid standard curve was created from a stock solution with a concentration of $100 \mathrm{mg} / \mathrm{mL}$ to make five gallic acid standard solutions of varying concentrations $(0.02,0.04,0.06,0.08$ and $0.10 \mathrm{mg} / \mathrm{mL})$. Next, $1 \mathrm{~mL}$ of each sample as well as diluted Mauby bark extracts were added to $25 \mathrm{~mL}$ volumetric flasks containing $9 \mathrm{~mL}$ of $\mathrm{DDH}_{2} \mathrm{O}$. After that, $1 \mathrm{~mL}$ of Folin-Ciocalteu (FC) reagent was added to the flask and mixed thoroughly. Furthermore, the samples were incubated at room temperature for 5 minutes then $10 \mathrm{~mL}$ of $7 \%$ Sodium Bicarbonate $\left(\mathrm{Na}_{2} \mathrm{CO}_{3}\right)$ solution was added to the mixture in each flask. Subsequently, the flasks were incubated for 90 minutes at ambient room temperature $\left(23^{\circ} \mathrm{C}\right)$. Next, the absorbance of each sample extract, which was orange-yellow in hue, was measured at a wavelength $750 \mathrm{~nm}$ using an UV spectrophotometer (Thermo Scientific AquaMate 8000 UV-Vis Spectrophotometer). Lastly, the TPC results were expressed as mg gallic acid equivalents (GAE)/mL Mauby bark extract using a standard curve. All samples were analyzed in triplicate and averaged for statistical analysis.

\subsection{Determination of the Free Radical Scavenging Activity of Mauby Bark Extract}

The free radical scavenging activity of Mauby bark extract was quantified according to a methodology described by Priyanka, Kadam, Ghule, and Aparadh (2013). First, $0.1 \mathrm{mM}$ DPPH (1, 1-Diphenyl-2-picryl-hydrazyl) was dissolved in $90 \%$ methanol in a beaker protected from light. Next, $1 \mathrm{~mL}$ of Mauby bark extract was added to 3 $\mathrm{mL}$ of the DPPH radical solution. Additionally, a control was made using $1 \mathrm{~mL}$ of methanol and $3 \mathrm{~mL}$ of the $\mathrm{DPPH} \bullet$ radical solution. Then, the solution was mixed and incubated at room temperature for 30 minutes in the dark. Afterwards, the DPPH $\bullet$ radical solution was analyzed using a UV Spectrophotometer (Thermo Scientific AquaMate 8000 UV-Vis Spectrophotometer) at a wavelength of $517 \mathrm{~nm}$. Next, the free radical scavenging activity was calculated as the percentage of free radicals able to be scavenged by the extract (Equation 1). Last, all sample extracts were analyzed in triplicate and averaged for analysis.

$$
\text { Inhibition of DPPH activity }(\%) \text { in Mauby }=\left(\mathrm{A}_{\text {control }}-\mathrm{A}_{\text {sample }} / \mathrm{A}_{\text {control }}\right) * 100
$$

\subsection{Determination of the Ferric Reducing Antioxidant Power (FRAP) of Mauby Bark Extract}

The total antioxidant power of Mauby bark extract was measured according to Abbasian et al. (2013) with slight modifications. First, Ferrous Sulfate $\left(\mathrm{FeSO}_{4}\right)$ standards $(0,3,6,9$ and $12 \mathrm{mM})$ were prepared to determine the antioxidant power of Mauby bark extract via a standard curve. Next, the FRAP reagent was made fresh as needed by combining three reagents in a 10:1:1 ratio namely: $300 \mathrm{mmol} / \mathrm{L}$ of acetate buffer $(\mathrm{pH} 3.6) ; 10 \mathrm{mmol} / \mathrm{L}$ of 2,4,6-tripryridyl-s-triazine (TPTZ) dissolved in $40 \mathrm{mmol} / \mathrm{L}$ hydrochloric acid ( $\mathrm{HCl}$ ), and $20 \mathrm{mmol} / \mathrm{L}$ of ferric chloride $\left(\mathrm{FeCl}_{3}\right)$ dissolved in $\mathrm{DDH}_{2} \mathrm{O}$. Then, $3.8 \mathrm{~mL}$ of the FRAP reagent was added to $200 \mu \mathrm{L}$ of Mauby bark extract into dark test tubes and incubated at $37^{\circ} \mathrm{C}$ in a temperature-controlled water bath for 5 minutes. Next, the absorbance of each sample extract was measured at an absorbance at a wavelength of $593 \mathrm{~nm}$ to test the total antioxidant capacity of reagents using a UV spectrophotometer (Thermo Scientific AquaMate 8000 UV-Vis Spectrophotometer). Last, the results were expressed as $\mathrm{mM} \mathrm{FeSO}_{4} / \mathrm{mL}$ Mauby extracts. All samples were analyzed in triplicate and averaged for analysis.

\subsection{Statistical Analysis}

All numerical data of this study was analyzed using the International Business Machine (IBM) Statistical Package for the Social Sciences (SPSS), Version 24. Moreover, the following analyses were used: one-way analysis of variance (ANOVA) to assess significance of polyphenolic quantity at 30, 45 and 60 minutes and Tukey's Honest Significance Difference (HSD) post-hoc to determine which time interval was significant upon significance of ANOVA. Lastly, the mean and standard deviation (SD) was completed for each chemical assay.

\section{Results and Discussion}

\subsection{Total Flavonoid Content (TFC) of Mauby Extracts}

The polyphenolic content of Mauby bark extracts was analyzed using the TFC and TPC assays. Specifically, flavonoids are a subcategory of polyphenols that comprise of six different classes: anthocyanins, flavanols, flavanones, flavones, flavonols, and isoflavones (Dai \& Mumper, 2010; Scalbert \& Williamson, 2000). The TFC assay signifies the total concentration $(\mathrm{mg} / \mathrm{mL}$ extract) of flavonoids in Mauby bark extracts as opposed to the 
individual sub classes which were previously mentioned. Notably, the mean TFC in Mauby bark extracts (Figure 2) in this present study ranged from a low of $24.13 \pm 2.13 \mathrm{mg} \mathrm{CE} / \mathrm{g}$ (60 minutes) to a high of $39.63 \pm 1.38 \mathrm{mg}$ $\mathrm{CE} / \mathrm{g}$ (30 minutes). After 30 minutes, there was a significant reduction in the total quantity of flavonoids suggesting that prolonged exposure to heat destroys polyphenolic compounds. Results from Tukey's HSD post-hoc suggest a significant $(p<0.001)$ difference in flavonoid content between brewing at 30 minutes to both 45 minutes and 60 minutes respectively, and a significant $(p=0.018)$ difference between brewing at 45 minutes and 60 minutes.

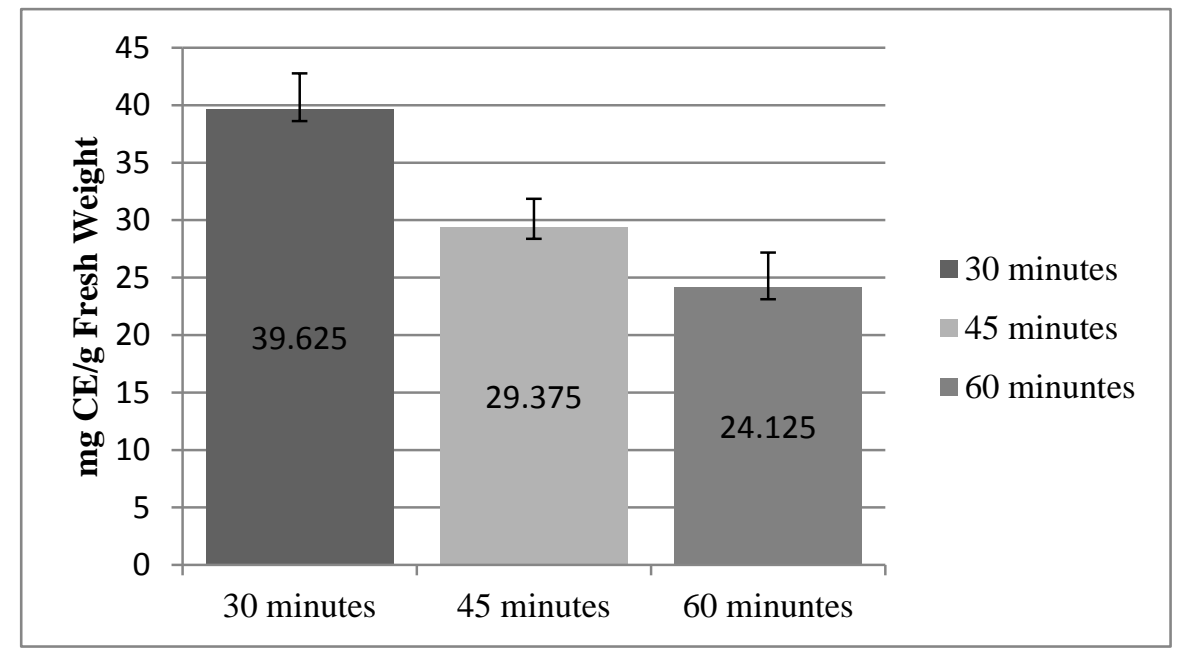

Figure 2. TFC results for Mauby extracts

Table 1. Tukey's HSD post-hoc analysis for TFC

\begin{tabular}{ll}
\hline Treatment Time & P Value \\
\hline Between 30 minutes and 45 minutes & $<0.001$ \\
Between 30 minutes and 60 minutes & $<0.001$ \\
Between 45 minutes and 60 minutes & 0.018 \\
\hline
\end{tabular}

$p \leq 0.05$ is significant

Mauby bark extract was observed to have a mean TFC of $31.04 \mathrm{mg} \mathrm{CE} / \mathrm{g}$. Bark extracts observed from other studies (Baliga, Pai, Bhat, Palatty, \& Boloor, 2011; Koti \& Ashok, 2010) have similar TFC content to Mauby bark extract. For instance, Mimusops elengi Linn., is a bark indigenously used in India and other South Asian countries as a diuretic. Additionally, M. elengi Linn can be used to treat cardiovascular disease (CVD) and contains antidiabetic and anticarcinogenic properties (Baliga, et al., 2011; Koti \& Ashok, 2010). The TFC content of M. elengi Linn was observed to have $23.55 \pm 0.80 \mathrm{mg}$ Quercetin Equivalents $(\mathrm{QE}) / \mathrm{g}$ (Mathur \& Vijayvergia, 2017). Another study (Dróżdż \& Pyrzynska, 2018) investigated the polyphenol content of oak bark (Quercus robust L.) extracts which has been used to treat skin diseases and found the TFC to range from $35.1 \pm 0.2 \mathrm{mg} \mathrm{CE} / \mathrm{g}$ to $38.0 \pm 1.1$. Additionally, oak bark is commercially available as a supplement that is rich in tannins, a subdivision of polyphenols, and is used extensively for its anti-inflammatory properties (Dawid-Pać, 2013).

\subsection{Total Phenolic Content (TPC) of Mauby Extracts}

From the experimental results, the mean TPC in Mauby bark extracts (Figure 3) ranged from a low of $26.21 \mathrm{mg}$ $\pm 1.38 \mathrm{GAE} / \mathrm{g}$ ( 45 minutes brewing time) to a high of $29.5 \pm 0.88 \mathrm{mg} \mathrm{GAE} / \mathrm{g}$ ( 30 minutes brewing time). Results from Tukey's HSD post-hoc suggest a significant $(p=0.002)$ difference in phenolic content between brewing at 30 minutes to both 45 minutes and 60 minutes respectively. However, no significant $(p=0.995)$ difference was observed between brewing at 45 minutes and 60 minutes. In contrast, Cinnamomum zeylanicum and Pinus maritima bark extracts have been observed by researchers to have higher TPC than Mauby bark which has a mean value of $27.29 \mathrm{mg} \mathrm{GAE} / \mathrm{g}$. In contrast, in a similar analysis of polyphenolic content, researchers (Ghitescu et al., 2015) observed that increases in time resulted with increased total polyphenolic extraction for spruce bark for up to 60 minutes using ethanol and water for extraction. However, a temperature of $50^{\circ} \mathrm{C}$ was used and the 
authors (Ghitescu et al., 2015) noted that increased time at high temperatures may initiate polyphenolic degradation. This may explain the decrease in TPC and TFC in Mauby bark after 30 minutes brewing at an extraction temperature $100^{\circ} \mathrm{C}$.

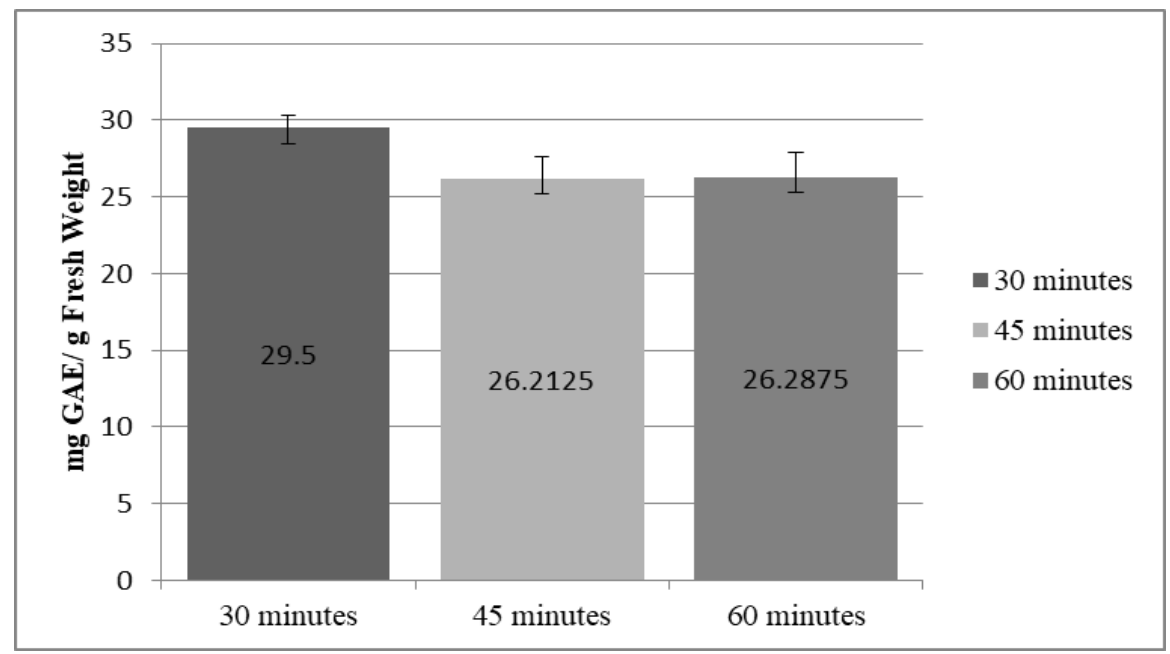

Figure 3. TPC results for Mauby extracts

Table 2. Tukey's HSD post-hoc analysis for Total Phenolic Content

$p \leq 0.05$ is significant

\begin{tabular}{lc}
\hline Brewing Time & P Value \\
\hline Between 30 minutes and 45 minutes & 0.002 \\
Between 30 minutes and 60 minutes & 0.002 \\
Between 45 minutes and 60 minutes & 0.995 \\
\hline
\end{tabular}

Notably, the TPC of C. zeylanicum and P. maritima were $309 \pm 0.05 \mathrm{mg} \mathrm{GAE} / \mathrm{g}$ and $360 \pm 0.04 \mathrm{mg} \mathrm{GAE} / \mathrm{g}$ (Dudonné, Vitrac, Coutiere, Woillex, \& Mérillon, 2009). C. zeylanicum is a spice also known as Ceylon Cinnamon that is beneficial in the treatment of diabetes, CVD and hypertension through lowering blood glucose, blood pressure and serum cholesterol (Ranasinghe, Pigera, Premakumara, Galappaththy, \& Constantine, 2013). P. maritima, sometimes referred to as French maritime pine bark, has further been observed to be a potent scavenger of ROS produced from hydrogen peroxide $\left(\mathrm{H}_{2} \mathrm{O}_{2}\right.$; Cho, Yun, Packer, \& Chung, 2001). In the food industry, supplements derived from procyanidin of P. maritima bark are among the most popular and extensively researched tree bark applications (Kähkönen et al., 1999).

In this study, a temperature of $100^{\circ} \mathrm{C}$ was used for polyphenolic extraction with noticeable declines in polyphenolic content as brewing time progressed. When compared to a temperature of $50^{\circ} \mathrm{C}$ used for polyphenolic extraction of the barks, C. zeylanicum and P. maritima, resulted in a higher TPC content. Therefore, temperatures above $50^{\circ} \mathrm{C}$ may be responsible for the decrease in TPC of Mauby bark. A comparison of TPC content of Mauby Bark to other known tree barks revealed that the TPC content of scotch pine bark (Pinus sylvestris) was $76 \pm 2.9 \mathrm{mg} \mathrm{GAE} / \mathrm{g}$, willow bark (Salix caprea) was $75.5 \pm 1.5 \mathrm{mg} \mathrm{GAE} / \mathrm{g}$, silver willow bark (Salix alba) was $58.6 \pm 0.9 \mathrm{mg} \mathrm{GAE} / \mathrm{g}$ and lastly, aspen bark (Populus tremula) was $32.1 \pm 0.2 \mathrm{mg} \mathrm{GAE} / \mathrm{g}$ (Kähkönen et al., 1999). While, it is true that some bark extracts have markedly higher TPC values than the Mauby bark extract, the bark extract of silver birch (Betula pendula) was observed to have $2.0 \pm 0.1 \mathrm{mg} \mathrm{GAE} / \mathrm{g}$ (Kähkönen et al., 1999). It is to be noted that the majority of the barks listed have applications as nutraceuticals.

\subsection{2,2 Diphenyl 1-Picrylhydrazyl (DPPH) Free Radical Scavenging Activity of Mauby Bark Extract}

The free radical scavenging activity of Mauby bark extract was measured by its ability to donate hydrogens to the DPPH• radical, thereby inhibiting it. Free radicals in the body which accumulate from diets low in antioxidants contribute to the oxidation of biomolecules such as DNA (Francisqueti et al., 1992). The inhibition of free radical scavenging capacity results from DPPH (Figure 4) ranged from $75 \pm 4.02 \%$ (30 minutes brewed) to $83 \pm 0.66 \%$ (60 minutes brewed) inhibition. A significant $(p=0.038)$ increase in free radical scavenging activity was observed between samples that were brewed for 30 minutes and 45 minutes, and between samples 
brewed for 30 minutes and 60 minutes $(p=0.014)$ (Table 3). These results suggest that as brewing time increases, the antioxidant activity of Mauby bark extract also increases. Therefore, the results suggest that brewing Mauby bark for prolonged times may allow for donation of electrons more effectively. Furthermore, data about other bark extracts as powerful antioxidants by scavenging free radicals were published in literature. The DPPH \% inhibition of $C$. zeylanicum bark and P. maritima bark were $84.43 \pm 3.48 \%$ and $94.51 \pm 0.01 \%$ respectively (Dudonné et al., 2009).

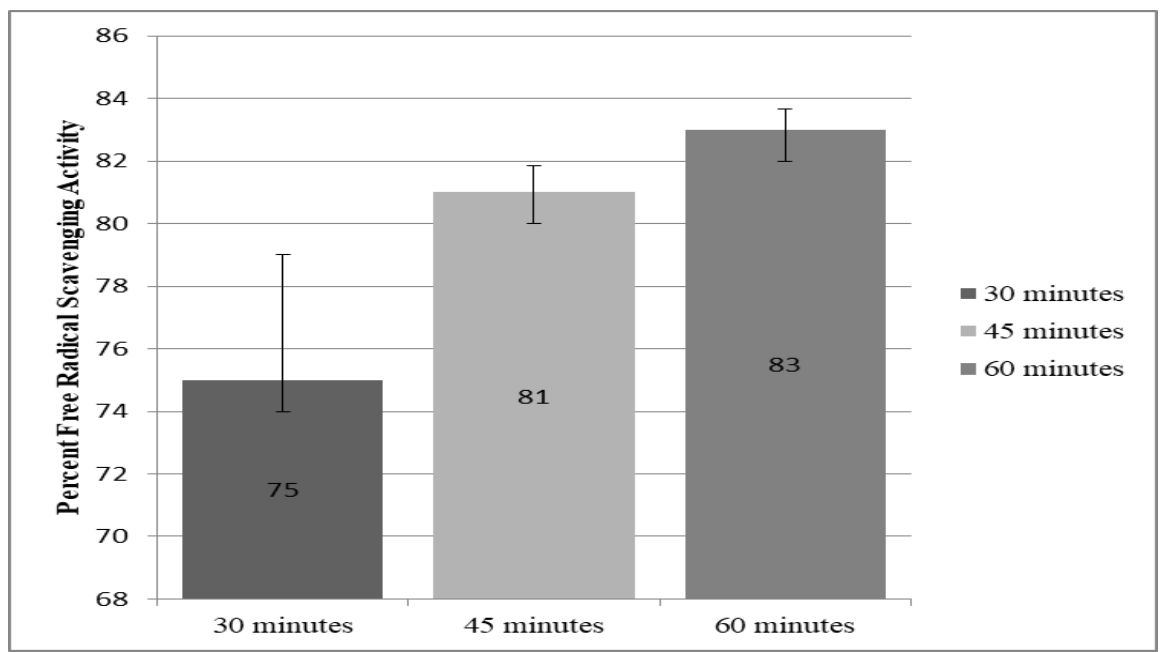

Figure 4. DPPH results for Mauby extracts

Table 3. Tukey's HSD post-hoc analysis for DPPH

\begin{tabular}{lc}
\hline Brewing Time & P Value \\
\hline Between 30 minutes and 45 minutes & 0.038 \\
Between 30 minutes and 60 minutes & 0.014 \\
Between 45 minutes and 60 minutes & 0.697 \\
\hline
\end{tabular}

$p \leq 0.05$ is significant

\subsection{Ferric Reducing Antioxidant Power (FRAP) of Mauby Bark Extract}

The antioxidant power of Mauby bark extracts derived from brewing times of 30, 45 and 60 mins to reduce ferric iron $\left(\mathrm{Fe}^{3+}\right)$ to ferrous iron $\left(\mathrm{Fe}^{2+}\right)$ was measured by the FRAP antioxidant assay. The ability of Mauby Bark extracts to reduce ferric iron directly relates to the antioxidant power of Mauby bark extract. The FRAP results (Figure 5) ranged from a low of $6.29 \pm 0.84 \mathrm{mM} \mathrm{FeSO}_{4}$ (30 minutes) to a high of $6.90 \pm 1.53 \mathrm{mM} \mathrm{FeSO}_{4}(45$ minutes) with no significant ( $\mathrm{p}=0.736$ ) difference between time brewed and antioxidant power. For this reason, it can be concluded that 60 minutes appears to be the ideal time to brew Mauby bark due to the highest increase in free radical scavenging activity in the DPPH assay and similarly antioxidant power among all the time intervals. The mean antioxidant power of Mauby bark extracts when converted to gram quantity $(0.105 \mathrm{mM} \mathrm{FeSO} / \mathrm{g})$ were slightly weaker than other barks. For example, the FRAP value of apple tree (Malus domestica) bark was $0.343 \mathrm{mM} \mathrm{FeSO} / \mathrm{g}$ when samples were extracted at $60^{\circ} \mathrm{C}$ (Withouck et al., 2017). Apple tree bark also contains the polyphenols such as phloretin which has been observed to contain antioxidant, anti-inflammatory, anticarcinogenic, antimutagenic and immunosuppressive properties (Xü, Lü, Qü, Shan, \& Song, 2010). Differences in FRAP values may be explained by geographic location and the ratio of antioxidant phytochemicals present within bark (Abuashwashi, Palomino \& Gómez-Serranillos, 2016). Conversely, when FRAP values are measured in $\mathrm{mL}$ quantities as Mauby is most commonly consumed as a beverage, Mauby bark extracts were observed to be more potent than tea extracts in FRAP values. The FRAP values for white tea (0.73 $\mathrm{mM} \mathrm{FeSO} / \mathrm{mL})$, green tea $\left(0.50 \mathrm{mM} \mathrm{FeSO} / 4 \mathrm{~mL}\right.$ and black tea $\left(0.38 \mathrm{mM} \mathrm{FeSO}_{4} / \mathrm{mL} ;\right.$ Al-Obaidi \& Sahib, 2015) are all markedly lower than Mauby extracts. However, there is limited research expressing FRAP values for bark extracts as $\mathrm{mM} \mathrm{FeSO}_{4}$ equivalents which allows these results to enhance existing literature. 


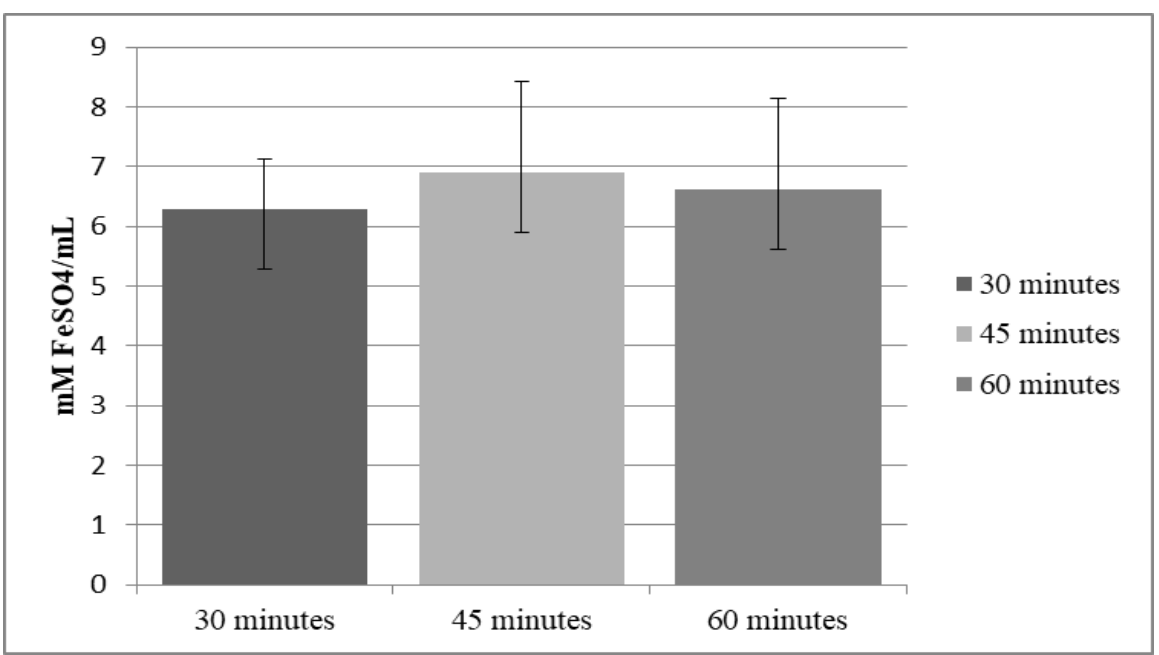

Figure 5. FRAP results for Mauby extracts

\section{Conclusion}

The experimental results of this study indicated that Mauby bark contains polyphenols that exhibit free radical scavenging activity that may protect against naturally occurring oxidative damage within the human body commonly implicated in the development of chronic illnesses. Evidently, for both TFC and TPC analyses, brewing of the bark for 30 minutes resulted in the highest quantity of polyphenols suggesting that increased exposure to heat will degrade polyphenols present in Mauby bark. The observed decrease in polyphenolic content however did not affect free radical scavenging activity at increasing brewing times suggesting that upon exposure to heat, the phenolics and flavonoids may be converted to other intermediate compounds or other compounds may be present in Mauby bark which may result in the higher antioxidant activity as brewing times increased. The brewing time recommended for Mauby Bark to provide the greatest antioxidant benefits is 60 minutes. Although at 30 minutes, the TPC and TFC values were greater than at 60 minutes, the free radical scavenging activity was found to be significantly higher at 60 minutes thus capable of performing as a more efficient antioxidant in the body. Results from this research can be used as a basis for product development of Mauby bark extracts infused into beverages to be sold in the United States of America. Further research is needed to characterize the specific polyphenolic compounds and derivatives that are responsible for the antioxidant capabilities of Mauby bark using techniques such as Mass Spectrometry (MS) and High Performance Liquid Chromatography (HPLC).

\section{Author Contributions}

J. Embola and C. Rock performed the experiments and collected data. J. Embola conducted data analysis and interpreted results. C. Rock, L. Wang, W. Reiboldt, S. Aliabadi and S. Ahmed reviewed and edited the manuscript that was written by J. Embola and C.Rock.

\section{References}

Abbasian, S., Karimi, F., Moghaddam, G., Soroush, A., Moloudian, H., \& Ahosseini, M. S. (2013). Antioxidant properties of different black tea samples and some Iranian native plants. Pharmacie Globale, 4(2), 1-5.

Abuashwashi, M. A., Palomino, O. M., \& Gómez-Serranillos, M. P. (2016). Geographic origin influences the phenolic composition and antioxidant potential of wild Crataegus monogyna from Spain. Pharmaceutical Biology, 54(11), 2708-2713.

Alleyne, T., Roache, S., Thomas, C., \& Shirley, A. (2005). The control of hypertension by use of coconut water and Mauby: Two tropical food drinks. The West Indian Medical Journal, 54(1), 3-8. https://doi.org/10.1590/S0043-31442005000100002

Al-Obaidi, R. S. S., \& Sahib, D. H. (2015). Determination of antioxidants activity in tea extract. American Journal of Biochemistry, 5(3), 49-52. https://doi.org/10.5923/j.ajb.20150503.01

Baliga, M. S., Pai, R. J., Bhat, H. P., Palatty, P. L., \& Boloor, R. (2011). Chemistry and medicinal properties of the Bakul (Mimusops elengi Linn): A review. Food Research International, 44(7), 1823-1829. https://doi.org/10.1016/j.foodres.2011.01.063 
Barbados Pocket Guide. (2011). Mauby drink. Retrieved from https://www.barbadospocketguide.com/eat-and-drink-in-barbados/bajan-food-and-drinks/mauby-drink.html

Cho, K. J., Yun, C. H., Packer, L., \& Chunga, A. S. (2001). Inhibition mechanisms of bioflavonoids extracted from the bark of Pinus maritima on the expression of proinflammatory cytokines. Annals of the New York Academy of Sciences, 928(1), 141-156. https://doi.org/10.1111/j.1749-6632.2001.tb05644.x

Dai, J., \& Mumper, R. J. (2010). Plant phenolics: Extraction, analysis and their antioxidant and anticancer properties. Molecules, 15(10), 7313-7352. https://doi.org/10.3390/molecules 15107313

D'archivio, M., Filesi, C., Di Benedetto, R., Gargiulo, R., Giovannini, C., \& Masella, R. (2007). Polyphenols, dietary sources and bioavailability. Annali Dell'Istituto Superiore Di Sanita, 43(4), 348.

Dawid-Pać, R. (2013). Medicinal plants used in treatment of inflammatory skin diseases. Advances in Dermatology and Allergology/Postępy Dermatologii I Alergologii, 30(3), 170-177. https://doi.org/10.5114/pdia.2013.35620

Dróżdż, P., \& Pyrzynska, K. (2018). Assessment of polyphenol content and antioxidant activity of oak bark extracts. European Journal of Wood and Wood Products, 76(2), 793-795. https://doi.org/10.1007/s00107-017-1280-x

Dudonné, S., Vitrac, X., Coutiere, P., Woillez, M., \& Mérillon, J. M. (2009). Comparative study of antioxidant properties and total phenolic content of 30 plant extracts of industrial interest using DPPH, ABTS, FRAP, SOD, and ORAC assays. Journal of Agricultural and Food Chemistry, 57(5), 1768-1774.

Francisqueti F. V., Chiaverini L. C., Santos K. C., Minatel I. O., Ronchi C. B., Ferron A. J., ... Corrêa, C. R. (1992). The role of oxidative stress on the pathophysiology of metabolic syndrome. Journal of Brazilian Medical Association, 63(1), 85-91. https://doi.org/10.1590/1806-9282.63.01.85

Ghitescu, R. E., Volf, I., Carausu, C., Bühlmann, A. M., Gilca, I. A., \& Popa, V. I. (2015). Optimization of ultrasound-assisted extraction of polyphenols from spruce wood bark. Ultrasonics Sonochemistry, 22, 535-541. https://doi.org/10.1016/j.ultsonch.2014.07.013

Johnston, M. (1971). Revision of colubrina (rhamnaceae). Brittonia, 23(1), 2-53. https://doi.org/10.2307/2805841

Kähkönen, M. P., Hopia, A. I., Vuorela, H. J., Rauha, J. P., Pihlaja, K., Kujala, T. S., \& Heinonen, M. (1999). Antioxidant activity of plant extracts containing phenolic compounds. Journal of Agricultural and Food Chemistry, 47(10), 3954-3962. https://doi.org/10.1021/jf9901461

Koti, B. C., \& Ashok, P. (2010). Diuretic activity of extracts of Mimusops elengi Linn. bark. International Journal of Green Pharmacy, 4(2), 90-92. https://doi.org/10.4103/0973-8258.63882

Manach, C., Scalbert, A., Morand, C., Remesy, C., \& Jimenez, L. (2004). Polyphenols: Food sources and bioavailability. American Journal of Clinical Nutrition, 79, 727-47. https://doi.org/10.1093/ajcn/79.5.727

Marinova, D., Ribarova, F., \& Atanassova, M. (2005). Total phenolics and total flavonoids in Bulgarian fruits and vegetables. Journal of the University of Chemical Technology and Metallurgy, 40(3), 255-260.

Mathur, R., \& Vijayvergia, R. (2017). Determination of total flavonoid and phenol content in mimusops elengi linn. International Journal of Pharmaceutical Sciences and Research, 8(12), 5282-5285. https://doi.org/10.13040/IJPSR.0975-8232.8(12).5282-85

Patel, D., Kumar, R., Laloo, D., \& Hemalatha, S. (2012). Diabetes mellitus: An overview on its pharmacological aspects and reported medicinal plants having antidiabetic activity. Asian Pacific Journal of Tropical Biomedicine, 2(5), 411-420. https://doi.org/10.1016/S2221-1691(12)60067-7

Priyanka, C., Kadam, D., Kadam A., Ghule, Y., \& Aparadh, V. (2013). Free radical scavenging (dpph) and ferric reducing ability (frap) of some gymnosperm species. International Journal of Research in Botany, 3(2), 34-36.

Ranasinghe, P., Pigera, S., Premakumara, G. S., Galappaththy, P., Constantine, G. R., \& Katulanda, P. (2013). Medicinal properties of "true" cinnamon (Cinnamomum zeylanicum): A systematic review. BMC Complementary and Alternative Medicine, 13, 275. https://doi.org/10.1186/1472-6882-13-275

Scalbert, A., \& Williamson, G. (2000). Dietary intake and bioavailability of polyphenols. The Journal of Nutrition, 130(8), 2073S-2085S. https://doi.org/10.1093/jn/130.8.2073S

Smith, C. (2012). Living with sugar: Influence of cultural beliefs on type 2 diabetes self-management of 
english-speaking afro-caribbean women. Journal of Immigrant and Minority Health, 14(4), 640-647. https://doi.org/10.1007/s10903-011-9513-2

Withouck, H., Boeykens, A., Lavigne, R., Luyten, W., Wagemans, J., Broucke, M.V. (2017). Phenolic composition, antimicrobial and antioxidant properties of apple wood extracts. Journal of Natural Product and Plant Resources, 7(3), 26-39. https://doi.org/10.13140/RG.2.2.34039.93609

World Agroforestry Centre [WAC]. (2009). Colubrina arborescens. Retrieved from http://www.worldagroforestry.org/treedb/AFTPDFS/Colubrina_arborescens.PDF

Xü, K., Lü, H., Qü, B., Shan, H., \& Song, J. (2010). High-speed counter-current chromatography preparative separation and purification of phloretin from apple tree bark. Separation and Purification Technology, 72(3), 406-409. https://doi.org/10.1016/j.seppur.2010.02.020

\section{Copyrights}

Copyright for this article is retained by the author(s), with first publication rights granted to the journal.

This is an open-access article distributed under the terms and conditions of the Creative Commons Attribution license (http://creativecommons.org/licenses/by/4.0/). 